\title{
Dynamic asphaltene deposition control in pipe flow through the application of DC potential
}

\author{
Muhammad Ihtsham Hashmi • B. Ghosh
}

Received: 14 September 2013/Accepted: 24 February 2014/Published online: 19 March 2014

(C) The Author(s) 2014. This article is published with open access at Springerlink.com

\begin{abstract}
Asphaltene-resin moieties in crude oil are found to carry residual surface electric charge, which is characteristics to their colloidal structure, asphaltene-resin ratio and system $\mathrm{pH}$. This research investigated the possibilities of controlling asphaltene deposition in oil well by applying static electrical potential taking advantage of their residual surface charge. Laboratory experiments were conducted at static and also in dynamic condition constructing a dual flow loop set-up, equipped with precision pumping, pressure recording and regulated DC power supply. Neat and heptane-diluted crude oil having inherent asphaltene deposition tendencies is used to investigate the influence of DC electrical potential on asphaltene deposition tendencies. Real time deposition trend is interpreted through differential pressure build-up across the flow loops and also through quantitative estimation of deposited mass. The results were encouraging, showing up to $180 \%$ reduction in asphaltene deposition in the cathode loop and about $140 \%$ increase on the anode loop at an optimised potential of $60 \mathrm{~V}$ DC. Further, it was observed that higher the $n$-heptane dilution, higher is the effect of static potential in terms of arresting deposition. Based on these optimistic results, further studies and upscaling are planned (considering the changes of pressure, temperature and fluid composition in an oil well) and looking at the possibilities of controlling asphaltene deposition, by converting the well into a cathode, along with a nearby sacrificing anode well, applying optimum electrical potential.
\end{abstract}

M. Ihtsham Hashmi $(\bowtie) \cdot$ B. Ghosh

Petroleum Engineering Department,

The Petroleum Institute, 2533, Abu Dhabi, UAE

e-mail: ihtsham@hotmail.com
Keywords Asphaltene - Oil · Flow assurance . Electrodeposition $\cdot$ Resin

\section{Introduction}

Asphaltenes in petroleum flow streams are often compared with low-density lipoproteins in blood stream, both being responsible for flow restriction, pressure surge and finally complete blockage, resulting system shut down owing to phase separation and deposition on the flow lines. In case of a petroleum production system, this may lead to permeability damage of the reservoir pore matrix, blocking production tubing, surface flow lines and fouling of surface equipment.

Asphaltene, the major constitution of the residue fraction of crude petroleum is commonly known as poly-condensed aromatic molecules of 4-10 rings (Groenzin and Mullins 2000) with multiple alkyl side chains. Heteroatomic (NSO) functional groups are the source of their polarity and amphoteric characteristics (Goual and Firoozabadi 2002), and the coordination metals ( $\mathrm{Fe}, \mathrm{Ni}, \mathrm{V}$ ) are confined within porphyrin type moieties (Speight 1998).

In general crude petroleum is a physical mixture of three major groups of compounds; asphaltenes are the largest in molecular size, resins fall in the mid range and the rest are the lighter aromatics and paraffins (maltenes). Asphaltenes and resins are polar, while the maltene compounds are either non-polar or mildly polar. The interaction among these species strongly affects asphaltene precipitation from petroleum fluids (Goual and Firoozabadi 2004).

Due to extremely wide molecular weight distribution and the ability to form molecular aggregates at different intensity at different chemical and physical condition, only average chemical structures and properties of asphaltenes and resins could be established so far. Stability of asphaltene

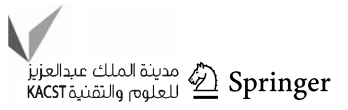


in crude oil depends upon a variety of factors (temperature, pressure, composition, $\mathrm{pH}$, etc.) of which resin content in oil is attributed to have the greatest influence (Andersen and Speight 2001). It is an established fact that petroleum resins with lesser aromaticity but higher polarity compared with asphaltene act as peptizing agents and help stabilizing asphaltene-resin colloids. The mechanism behind this molecular association is believed to be due to opposite surface charge of resins and asphaltene moieties (Taylor 1998). It is observed that destabilization of colloidal asphaltene in oil production systems may occur if the surface charge and the resulting attraction forces between adsorbed resins and asphaltenes are disturbed (Leontaritis 1989; Alkafeef 2001). Later works of Fotland and Anfindsen (1996) and Behar et al. (1998) on electrical conductivity of asphaltene helped in understanding their molecular association phenomena in solution phase, while works of Igor and Aleksander (2010) on electrical conductivity of solid asphaltenes showed that asphaltenes in solid state behave like semiconductors, conductivity increasing at higher temperature, possibly due to structural phase transition.

Electrokinetic, electrophoretic and adsorption properties of asphaltenes are studied through potentiometric and electrokinetic measurements in great details on various crude oils which firmly established its charge-bearing properties and streaming potential (Kokal et al. 1995; Leon et al. 2000; Gonzalez et al. 2003; Parra-Barraza et al. 2003). Asphaltenes in aqueous solutions are found to possess surface charge as a result of protonation and dissociation reactions of functional groups enabling electrophoretic mobility (Janusz and Jablonski 2000). Solventinduced polarity is seen to reverse the electrophoretic mobility of destabilized asphaltene particles. Dispersed in polar (water) media, the particles presented a negative electrophoretic mobility, whereas in toluene their mobility was positive. When resins were present in the precipitating medium, co-precipitation of resins occurred, indicating a binding process of the resins on the nascent asphaltene particles (Parra-Barraza et al. 2003).

Due to the dependency of several factors (solvent, temperature and influence of resins), the nature of native surface charge on asphaltene is still not fully established. Whereas some researchers claimed that asphaltene possess a predominantly positive charge in most non-aqueous dispersants (James and Richard 1963; Lichaa and Herrera 1975; Leon et al. 2000; Gonzalez et al. 2003), some reported their net negative surface charges based on electro-deposition experiments with neat crude oil samples (Idem and Ibrahim 2002; Nasser and Belhaj 2010; Belhaj and Khalifeh 2013). Also noteworthy is the work of Leontaritis and Mansoori (1987) who showed that the net negative charge on asphaltene colloidal surface is the prime cause of deposition on metal pipes due to the potential difference across them. This resulted with the hypothesis that, any effort in neutralising this charge may result in controlling asphaltene precipitation and deposition (Yen 1994). Leon et al. (2000) from their electrophoretic mobility studies with 27 crude oils established that the surface charges on asphaltene micelles were predominantly negative in crude oils and at low heptanes dilution but the surface charges were reversed at higher dilution. The charge reversal was attributed to removal of positively charged peptizing resins. Khvostichenko and Andersen (2009) investigated the charge reversal phenomenon under various conditions of dilution and found that application of a DC electric field can arrest asphaltenes aggregation or precipitation when diluted in aromatic solvent (toluene).

Taylor (1998) studied the quantum of electro-deposition of asphaltene and resins as a function of the electric field strength, residence time, dilution ratio and oil type. It was observed that stable asphaltene 'micelles' in crude oils possess little net charge and are apparently not affected by the DC electric field. However, upon partial or total destabilization of micelles with $n$-alkanes, electro-deposition occurred, depending on the crude oil characteristics, alkane used and their relative dilution. At lower dilutions (partial destabilization), the deposited material possesses a small net negative charge; higher dilutions resulted in a positively charged deposit. Although these findings are in contradiction with some of the observations described above, they are consistent with the structural model for asphaltene micelles comprising negatively charged 'peptizing' resins surrounding a positively charged central asphaltene core. The ambiguities existing on the surface charge of asphaltene and resins have been clarified by the work of Hashmi and Firoozabadi (2012) in which they have concluded that asphaltene colloids may possess heterogeneous surface charge. Some particles may carry a small net positive charge that can deposit on cathode, while others may carry a small net negative charge that can deposit on anode surface. Metallic components, pi-electron clouds and acid-base functional groups on the periphery contribute to the surface charge which may vary from crude to crude depending on source, maturation and migration history of the oil.

From the above discussion, it is evident that the subject needs extensive and systematic research to understand the mechanisms that generate the asphaltene surface charge and the physical conditions which may have impact on them. In this study, a new approach is adopted in which the rate of asphaltene deposition is measured in static and dynamic (flowing) condition under variable DC electric potential, using dead crude oil samples from selected Abu Dhabi reservoirs where frequent asphaltene deposition in the downhole production tubing and surface flow lines is a potential flow assurance problem. Oil samples are diluted with $n$-heptane at different ratios to mimic oil swelling at 
different production nodes. The work is focused on understanding the behaviour of surface charge potential of stabilised and destabilised (due to dilution) asphaltene as well as investigating the possibilities of controlling the rate of asphaltene deposition in flow lines by the application of DC electric potential. To achieve these objectives, a dynamic dual loop flow system was constructed, equipped with precision syringe pump, differential pressure transducers with data acquisition system and a DC power supply system with voltage regulator. Oil samples were flown for a long time till equilibrium is reached between deposition rate inside the tube surface and dislodgement due to pressure surge and corresponding differential pressure across the individual loops remained nearly constant. Further experiments were conducted to understand the effect of solvent stripping mechanism of asphaltene-resin moieties and the shielding effect of resin, using oil samples diluted with various ratios of $n$-heptane.

\section{Materials and methods}

\section{Crude oil}

Crude oil sample form Arab-X field was collected in sealed container under nitrogen environment, vacuum degassed, dewatered through centrifugation and finally filtered through $0.2-\mu \mathrm{m}$ membrane filter (Millipore) to remove suspended materials if any. Three oil samples were prepared mixing crude oil and $n$-heptane (Sigma-Aldrich) in 100:0, 80:20 and 50:50 ratios to represent oil in its original state, maximum saturate expansion at bubble point and a severe dilution scenario under natural gas injection. These samples will be identified as neat oil, 80:20 oil and 50:50 oil. All experiments were conducted at $20 \pm 1{ }^{\circ} \mathrm{C}$.

The asphaltene content of the crude oil was measured by mixing the petroleum fluid with heptane at $40 \mathrm{~mL} / \mathrm{g}$. The mixtures are sonicated for $1 \mathrm{~min}$ and filtered through $0.2-$ $\mu \mathrm{m}$ membrane filter. The filtrate is collected, dried and weighed to determine the fraction of asphaltenes in the oil. SARA (saturates, aromatics, resins and asphaltenes) analysis of the crude oil is conducted using standard method (IP-469). Anton Paar Elementar is used for elemental analysis of the crude oil. Detail properties of the crude oil are given in Table 1.
Static or base experiments

In order to establish that the asphaltene moieties in the sample crude oil bear excess surface charge and electrical attractive forces can have impact on their electrophoresis and deposition behaviour, a series of static electro-deposition experiments were conducted on a specially designed double half-cell apparatus (Fig. 1). Oil was placed in two separate temperature controlled plastic cells of $250 \mathrm{~mL}$ capacity, each having a graphite electrode $(12 \mathrm{~cm}$ in length and $0.8 \mathrm{~cm}$ in diameter), one connected to the positive terminal and the other to the negative terminal of a DC power source (maximum capacity of $300 \mathrm{~V}$ ). Static potentials of 20,50,100, 150 and $200 \mathrm{~V}$ were applied across these electrodes. Asphaltene deposition was studied up to $30 \mathrm{~h}$. Finally, the electrodes were removed from the cells and inspected visually for asphaltene deposition, and quantitative measurements were conducted following ASTM D2007-80 method, i.e. dissolving in toluene and reprecipitating with excess $n$-heptane. In addition to understanding the nature of asphaltene and resin characteristics, these experiments helped in optimising the voltage and deposition time for next phase of experiments.

Dynamic flow studies

Schematic diagram of the experimental set-up used for the dynamic flow studies is given in Fig. 2. The main section of the set-up consists of two spiral loops (designated as test loop A and B, made of stainless steel tubes (length $10 \mathrm{ft}$, OD $\frac{1}{4}$ and ID $\frac{1}{8}$ in.). Both the loops were fitted with highly sensitive pressure transducers along with data acquisition system. One of the loops is connected to the negative terminal and the other to the positive terminal of a table top DC power source. Two floating piston cylinders A and B, each having a capacity of 2,000 $\mathrm{mL}$ were used to store and flow crude oil through the test loops. While one cylinder is put in pumping mode, the other cylinder is in receiving mode that way nearly continuous flow could be maintained. A dual (continuous mode) ISCO 260D positive displacement pump was used to inject the test fluid into the test loops through the piston cylinders. The set-up used several valves, so that continuous pumping of oil through the test loops could be possible with minimum flow interruption. Stainless steel tubes were substituted by high-pressure

Table 1 Properties of the test crude oil

\begin{tabular}{|c|c|c|c|c|c|c|c|c|c|}
\hline $\begin{array}{l}\text { Specific } \\
\text { gravity at } \\
60^{\circ} \mathrm{F}\end{array}$ & $\begin{array}{l}\text { Kinematic viscosity } \\
\text { at } 70^{\circ} \mathrm{F}(\mathrm{Cst})\end{array}$ & $\begin{array}{l}\text { Total acid number } \\
(\mathrm{mg} \mathrm{KOH} / \mathrm{gm})\end{array}$ & $\begin{array}{l}\text { Sulphur } \\
\text { content } \\
(\mathrm{wt} \%)\end{array}$ & $\begin{array}{l}\mathrm{N}_{2} \\
\text { content } \\
(\mathrm{wt} \%)\end{array}$ & $\begin{array}{l}\mathrm{O}_{2} \\
\text { content } \\
(\mathrm{wt} \%)\end{array}$ & $\begin{array}{l}\text { Saturates } \\
(\mathrm{wt} \%)\end{array}$ & $\begin{array}{l}\text { Aromatics } \\
(\mathrm{wt} \%)\end{array}$ & $\begin{array}{l}\text { Resins } \\
(\mathrm{wt} \%)\end{array}$ & $\begin{array}{l}\text { Asphaltenes } \\
(\mathrm{wt} \%)\end{array}$ \\
\hline 0.826 & 4.32 & 0.021 & 1.32 & 0.03 & 4.28 & 70.56 & 25.08 & 3.93 & 0.42 \\
\hline
\end{tabular}




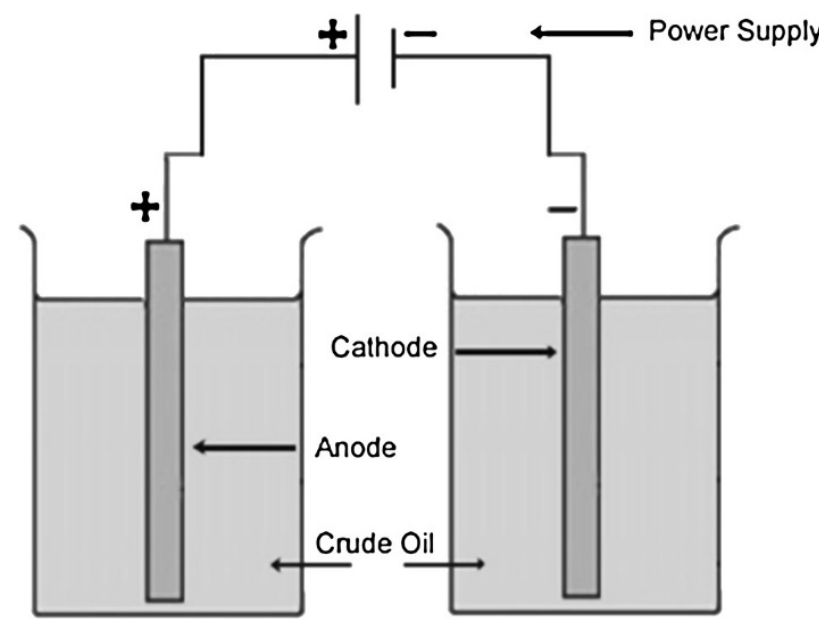

Fig. 1 Static experiment for the characterisation of charge-bearing properties of asphaltene

plastic tubes at different locations to make sure that the loops and pumping sections are electrically isolated.

Using this flow set-up, a series of dynamic electrodeposition tests were conducted using neat crude oil as well as crude oil diluted with $n$-heptane at 80:20 and 50:50 ratios. For each run, $30 \mathrm{~L}$ of test fluid was flown through the loops at a constant flow rate of $5 \mathrm{~mL} / \mathrm{min}$ (laminar flow regime). In addition to blank runs, tests were conducted applying DC potential until the optimum voltage requirement is reached. All tests were conducted in duplicate interchanging the polarity of the loops and average readings were taken. This measure nullified error due to positional advantage of the loops. During the flow period, change of differential pressure across the loops was measured and plotted. On completion of the flow period, the coils were cleaned thoroughly with hot toluene, and total asphaltene content is measured following standard methodology (ASTM D2007-80). Three sets of tests were conducted as follows: (A) with neat oil, (B) crude oil partially destabilised by $25 \%$ dilution with heptane and (C) crude oil fully destabilised with $100 \% n$-heptane.

\section{Results and discussion}

\section{Elemental analysis}

Analytical results given in Table 1 show that the sulphur and oxygen contents of the sample crude oil are much higher compared with nitrogen. It is a common knowledge that NSO functional groups are generally concentrated in asphaltene and resin fraction of the crude oil. In asphaltenes, they are found mostly as polar functional groups on the molecule itself, inducing polarity. The resin fraction being a complex mixture, they may, however, be present as long-chain carboxylic or sulphur-containing acids and nitrogen-containing basic compounds among numerous others. From the elemental analysis, it is apparent that the presence of N-containing basic functional groups (which give rise to positive surface charge) is expected to be significantly less than the S- and O-containing acidic functional groups (which contribute to negative surface charge).

Fig. 2 Schematic of experimental set-up for asphaltene deposition study

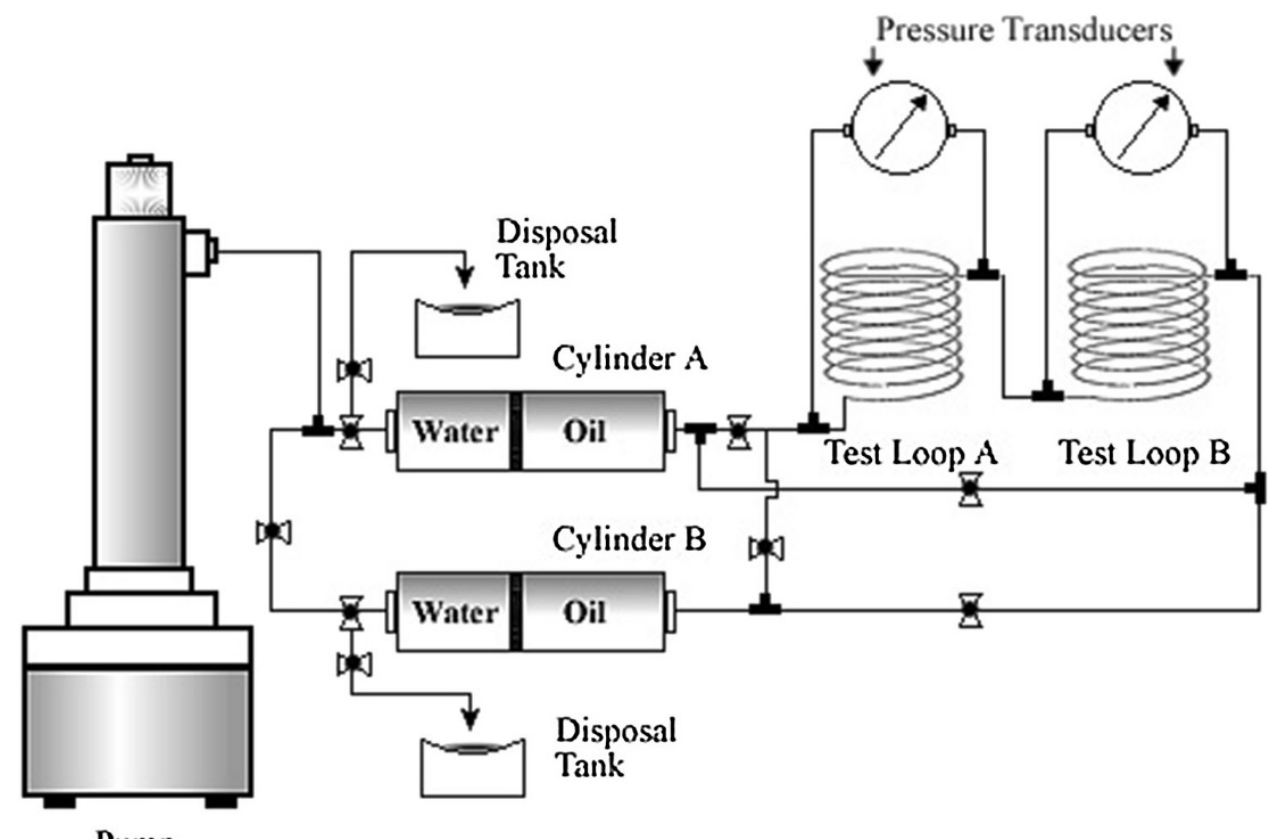

Pump 
SARA and colloidal instability index

From the SARA (saturates, aromatics, resins and asphaltenes) analysis results, we can calculate the colloidal instability index or CII of the oil, which is an empirical measure of stability of asphaltene in a crude oil system.

$\mathrm{CII}=($ Saturates + Asphaltenes $) /($ Aromatics + Resin $)$

It is observed that when $\mathrm{CII}<1.0$, the combined presence of resins and aromatics in oil is sufficient to stabilise the asphaltenes in crude. Presence of higher ratio or addition of saturates or removal of aromatics enhances $\mathrm{CII}$ value and reduces the asphaltene stability (Asomaning and Watkinson 2000).

It can be seen that CII value of the crude oil used in this study is 2.44 indicating that the crude oil is colloidally unstable and the possibility of asphaltene precipitation and deposition exists if suitable physical condition is available.

Static electro-deposition studies

Static electro-deposition experiments were conducted with three oils in a truly static condition (in terms of mechanical agitation and flow of current). DC potential was increased progressively to understand the threshold and optimum voltage requirement. Results of the 12 static jar tests are given in Table 2. In all the experiments, deposition of asphaltene like solids was observed on anode only, indicating that the deposited materials bear a net negative surface charge. The threshold voltage required to initiate precipitation was found to reduce with increasing oil dilution. Increase in DC potential resulted in an increase in the deposition rate on anode, no deposition was observed on the cathode electrode. Optimum voltage is seen to be

Table 2 Test data on the electro-deposition of asphaltene at static condition on anode and cathode

\begin{tabular}{|c|c|c|c|c|}
\hline $\begin{array}{l}\text { Test } \\
\text { no. }\end{array}$ & $\begin{array}{l}\text { Oil-heptane } \\
\text { ratio }\end{array}$ & $\begin{array}{l}\mathrm{DC} \\
\text { potential }\end{array}$ & $\begin{array}{l}\text { Deposit at anode } \\
\text { (mg) }\end{array}$ & $\begin{array}{l}\text { Deposit at } \\
\text { cathode }\end{array}$ \\
\hline SA1 & Neat & 40 & Not detectable & Not detectable \\
\hline SA2 & Neat & 80 & 13 & Not detectable \\
\hline SA3 & Neat & 120 & 47 & Not detectable \\
\hline SA4 & Neat & 160 & 39 & Not detectable \\
\hline SB1 & $80: 20$ & 40 & 29 & Not detectable \\
\hline SB2 & $80: 20$ & 80 & 57 & Not detectable \\
\hline SB3 & $80: 20$ & 120 & 63 & Not detectable \\
\hline SB4 & $80: 20$ & 160 & 54 & Not detectable \\
\hline $\mathrm{SC} 1$ & $50: 50$ & 40 & 42 & Not detectable \\
\hline $\mathrm{SC} 2$ & $50: 50$ & 80 & 93 & Not detectable \\
\hline $\mathrm{SC} 3$ & $50: 50$ & 120 & 113 & Not detectable \\
\hline $\mathrm{SC} 4$ & $50: 50$ & 160 & 127 & Not detectable \\
\hline
\end{tabular}

Table 3 Test data on the dynamic electro-deposition on anode and cathode coils

\begin{tabular}{llrllll}
\hline Test no. & $\begin{array}{l}\text { Oil to } \\
\text { heptane } \\
\text { ratio }\end{array}$ & $\begin{array}{l}\text { Static } \\
\text { potential } \\
(\mathrm{v})\end{array}$ & $\begin{array}{l}\Delta \mathrm{P} \\
\text { across } \\
\text { anode } \\
\text { (psid) }\end{array}$ & $\begin{array}{l}\Delta \mathrm{P} \\
\text { across } \\
\text { cathode } \\
\text { (psid) }\end{array}$ & $\begin{array}{l}\text { Deposit } \\
\text { at anode } \\
(\mathrm{mg})\end{array}$ & $\begin{array}{l}\text { Deposit at } \\
\text { cathode } \\
(\mathrm{mg})\end{array}$ \\
\hline DA-1 & Nil & 0 & 0.024 & 0.012 & 142 & 118 \\
DA-2 & Nil & 20 & 0.025 & 0.021 & 150 & 119 \\
DA-3 & Nil & 40 & 0.023 & 0.030 & 173 & 116 \\
DA-4 & Nil & 60 & 0.079 & 0.022 & 176 & 108 \\
DA-5 & Nil & 80 & 0.094 & 0.031 & 178 & 122 \\
DA-6 & Nil & 100 & 0.091 & 0.033 & 181 & 117 \\
DB-1 & $80: 20$ & 0 & 0.136 & 0.068 & 328 & 298 \\
DB-2 & $80: 20$ & 20 & 0.176 & 0.026 & 362 & 204 \\
DB-3 & $80: 20$ & 40 & 0.195 & 0.023 & 392 & 184 \\
DB-4 & $80: 20$ & 60 & 0.170 & 0.03 & 415 & 169 \\
DB-5 & $80: 20$ & 80 & 0.162 & 0.012 & 399 & 151 \\
DC-1 & $50: 50$ & 0 & 0.25 & 0.20 & 654 & 553 \\
DC-2 & $50: 50$ & 20 & 0.345 & 0.07 & 819 & 238 \\
DC-3 & $50: 50$ & 40 & 0.405 & 0.09 & 896 & 162 \\
DC-4 & $50: 50$ & 60 & 0.51 & 0.05 & 923 & 127 \\
DC-5 & $50: 50$ & 80 & 0.55 & 0.047 & 929 & 127 \\
\hline
\end{tabular}

between 80 and $120 \mathrm{~V}$ for all the oil samples. These observations lead us to believe that the asphaltene fraction in the crude oil possess excess negative charge which increases progressively with heptane dilution. Since asphaltene micelles are attracted by the anode, it would be reasonable to assume that cathode will repel the asphaltenes and inhibit their deposition. These results were used as a guiding factor in conducting further studies in dynamic condition.

Electro-deposition behaviour in dynamic or flowing condition

During electro-deposition studies at dynamic condition, we were careful in maintaining oil flow rate in the laminar region to avoid erosion of the expected deposits. Each study was conducted for about $10 \mathrm{~h}$, circulating nearly $30 \mathrm{~L}$ of oil through each flow loop. DC voltage was applied, progressively stepping up in each subsequent test till no further enhancement of either deposition rate or deposited quantity was observed. As mentioned earlier, measurement of differential pressure across the flow loops was the means of monitoring real time deposition rate, while quantitative assessment of net deposition was conducted at the end of each experiment through tube cleaning and re-precipitation method. Results of the asphaltene deposition behaviour of the three oils across the anode and cathode loops under various DC potential are given in 

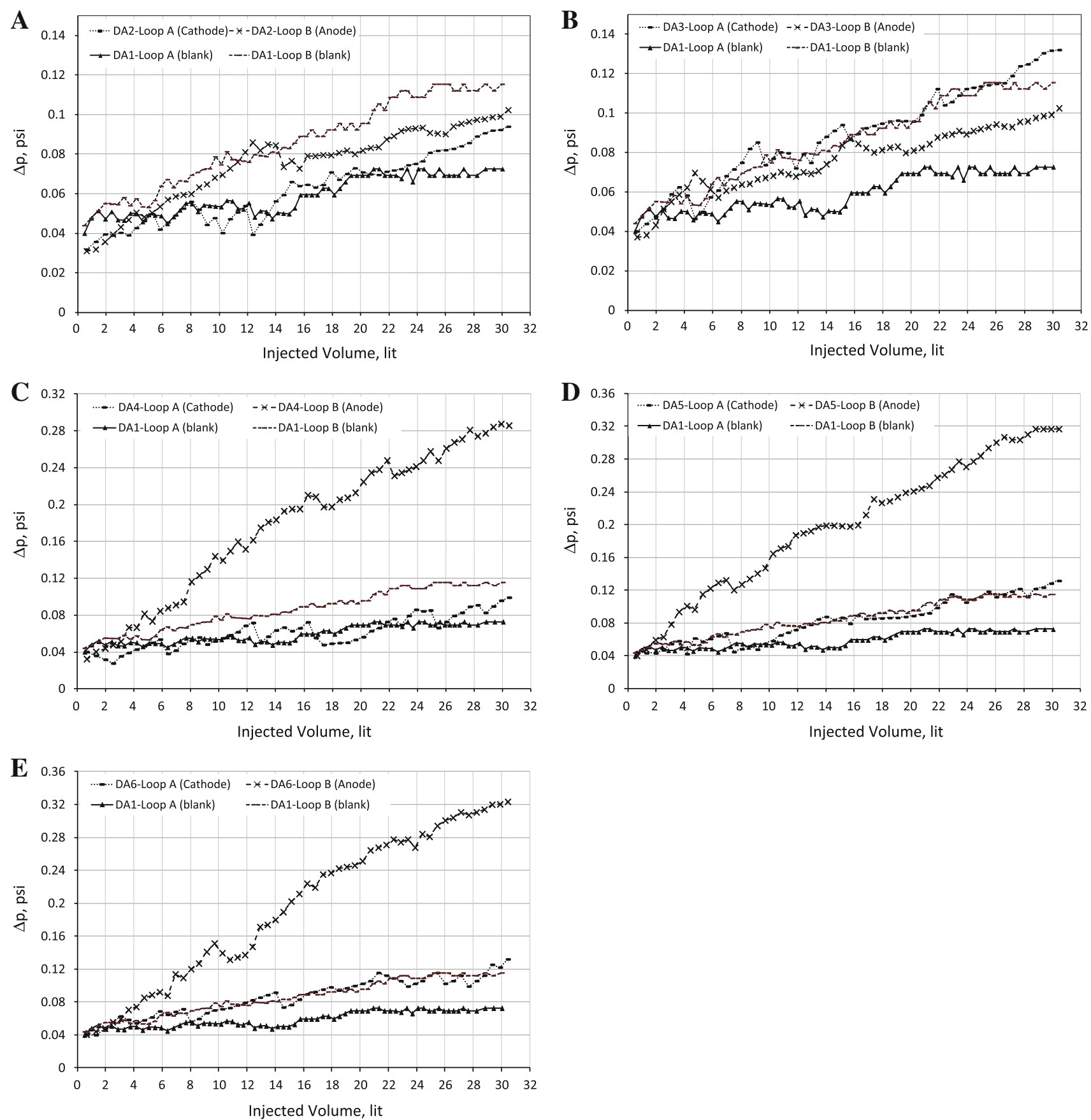

Fig. 3 a Pressure build-up during blank DA-1 and test DA-2 (20 V, neat oil). b Pressure build-up during blank DA-1 and test DA-3 (40 V, neat oil). c Pressure build-up during blank DA-1 and test DA-3

(60 V, neat oil). d Pressure build-up during blank DA-1 and test DA-4 ( $80 \mathrm{~V}$, neat oil). e Pressure build-up during blank DA-1 and test DA-5 $(100 \mathrm{~V}$, neat oil)

Table 3. It must be mentioned at this stage that the current flow in these experiments was bare minimum (1-3 mA); thus, the electric field applied on the flow tubes can be considered as static potential.

Figure 3a through $3 \mathrm{e}$ depicts the dynamic electrodeposition of the neat oil under DC potential of $0,20,40$, 60,80 and $100 \mathrm{~V}$, respectively. Similarly, the figure in $4 \mathrm{a}$ through $4 \mathrm{~d}$ and Fig. 5a through $5 \mathrm{~d}$ are graphical

representation of the experimental results, when 80:20 and 50:50 oils were used for investigation.

It appears from the blank test with neat oil (Exp. DA-1) that precipitation and deposition of asphaltene on its flow path are influenced not only due to solvent dilution but also due to sedimentation potential and/or streaming potential arising due to the flow through the metal tube. (Sedimentation potential is an electrical potential arises due to the 

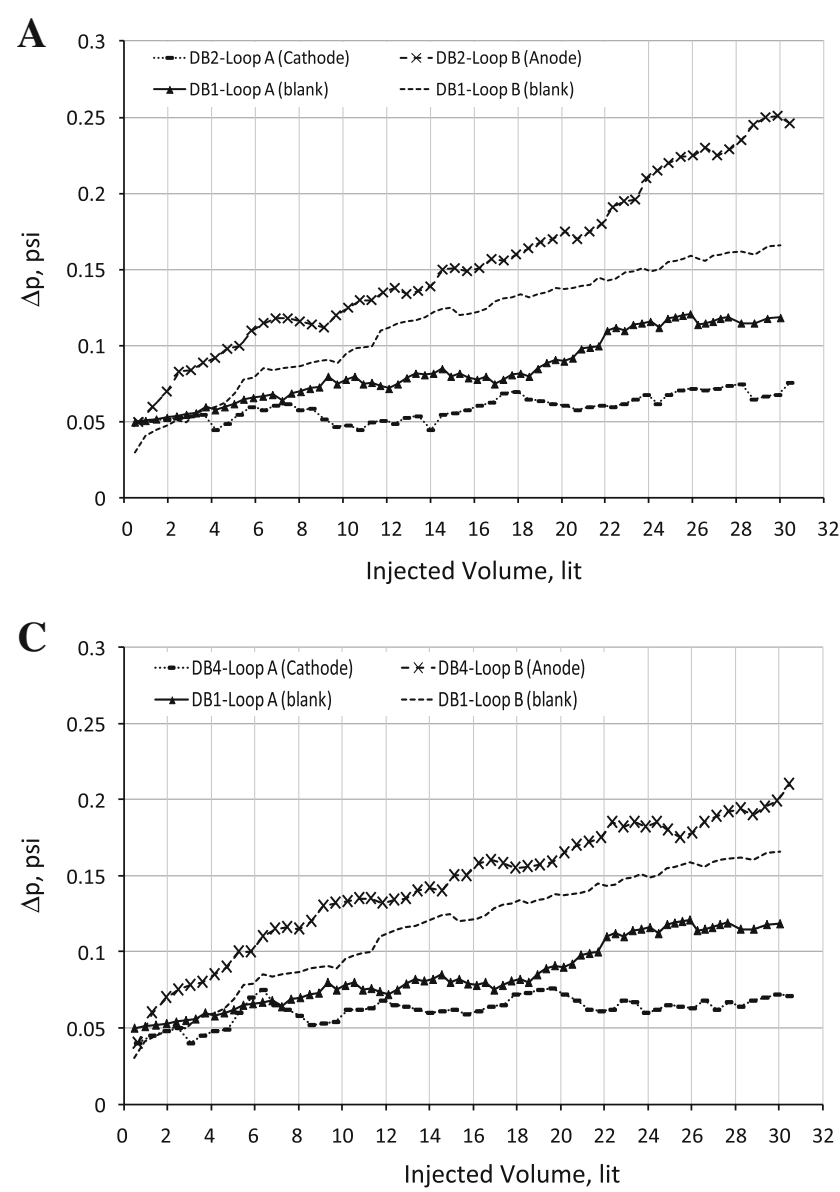

Fig. 4 a Pressure build-up during blank DB-1 and test DB-2 (20 V, 80:20 oil). b Pressure build-up during blank DB-1 and test DB-3 (40 V, 80:20 oil). c Pressure build-up during blank DB-1 and test

movement of charged particles through a liquid by gravity or pressure differential, and Streaming potential is the electric potential generated when a liquid is forced to move along a stationary charged surface). From CII value, we have established that the crude oil is supposed to be colloidally unstable. However, on long-term storage, we did not find sedimentation at the bottom of the bottle, indicating that at static condition the asphaltene particles are either small enough to enable sedimentation or due to similar surface charges they generate sufficient repelling force to prevent colloidal association and sedimentation. This observation explains the reason of blockage of production tubing even though the oil looks stable at laboratory condition. In subsequent flow studies, when the oil was flown through a charged surface (Exp. DA-2-DA-6, Fig. 3a through 3e), the asphaltene colloids were subjected to an increasingly stronger streaming potential in addition to its inherent sedimentation potential, resulting larger amount of asphaltene deposition. This is evident from the increase in differential pressure across the anode loop (as well as larger quantities of deposited mass). Important and
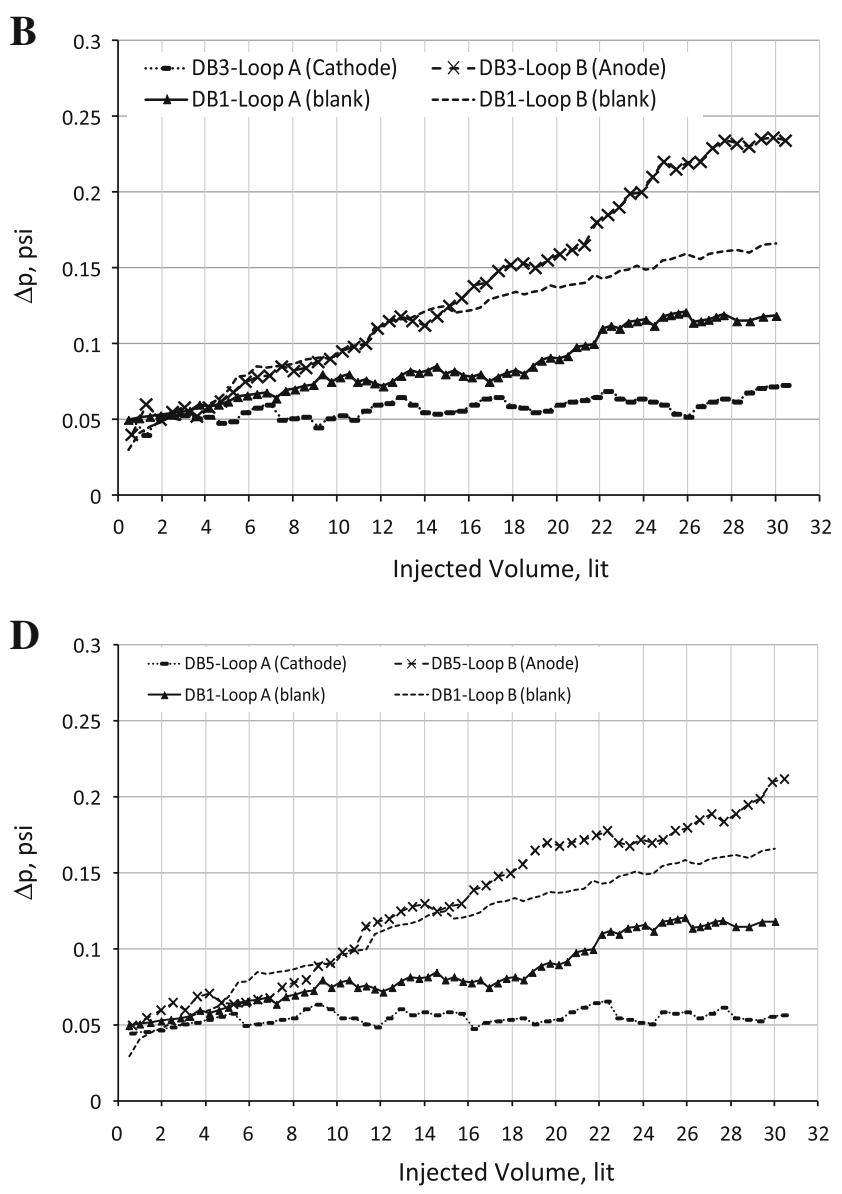

DB-4 (60 V, 80:20 oil). d Pressure build-up during blank DB-1 and test DB-4 $(80 \mathrm{~V}, 80: 20$ oil)

notable facts observed form these comparative plots are prominence of asphaltene deposition on the anode loop only and almost no deposition on the cathode loop, strongly suggesting negative residual charge of the asphaltene colloids. Electro-deposition behaviour of the heptane-diluted samples was found to be similar but more pronounced than the neat oil. The blank experiments (DB-1 and DC-1) yielded faster and more asphaltene deposition compared with neat oil (Table 3), and upon application of DC potential, the rate of deposition and quantity of deposits (on anode) increased proportionately with little or no deposition on the cathode loops (Fig. 4a through 5d). To understand the combined effect of heptane dilution and application of static potential, we refer to Fig. 6, which represents comparative analysis of all the flow studies in terms of deposited mass compared with blank experiments with same oil. It is evident from this figure that as the deposition on the anode is progressively increasing with higher static potential, higher level of deposition control can be achieved on the cathode loop. Also, it is evident that control of asphaltene deposition is more prominent when 

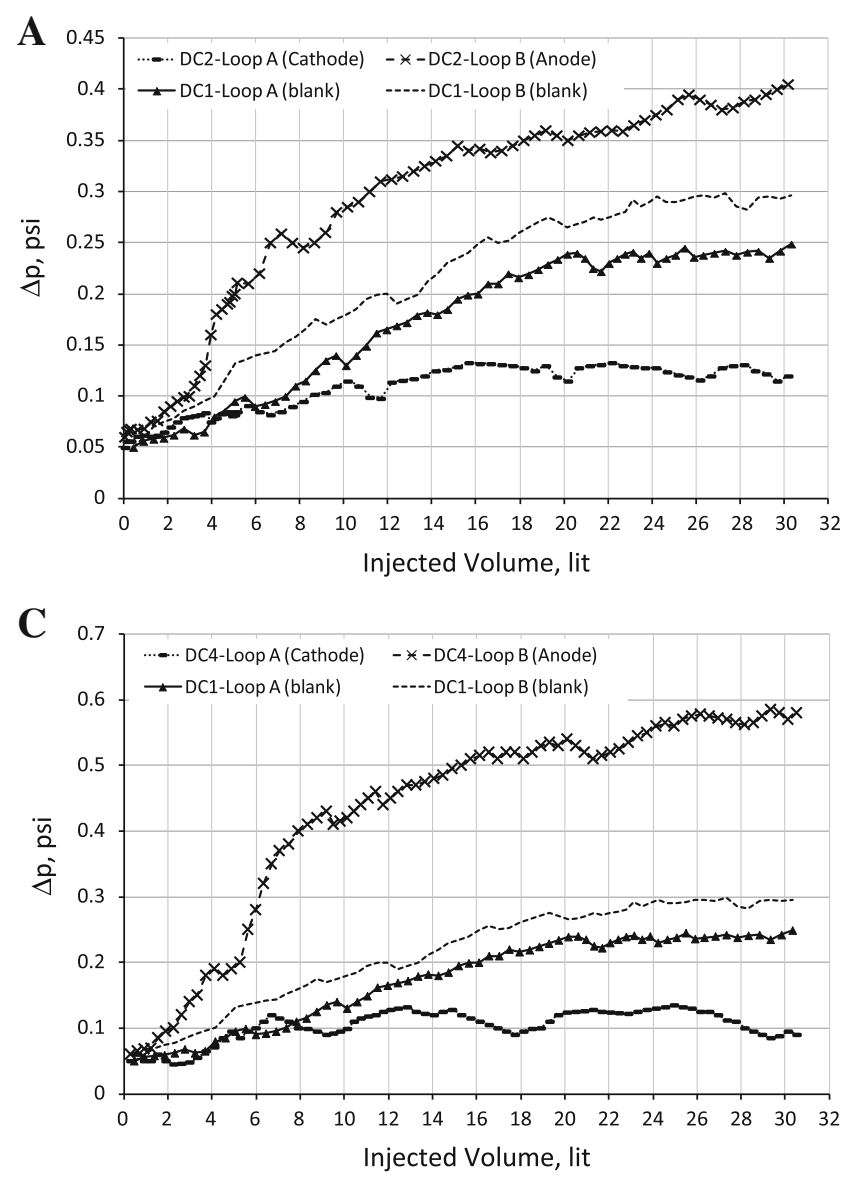

Fig. 5 a Pressure build-up during blank DC-1 and test DC-2 (20 V, 50:50 oil). b Pressure build-up during blank DC-1 and test DC-3 (40 V, 50:50 oil). c Pressure build-up during blank DC-1 and test

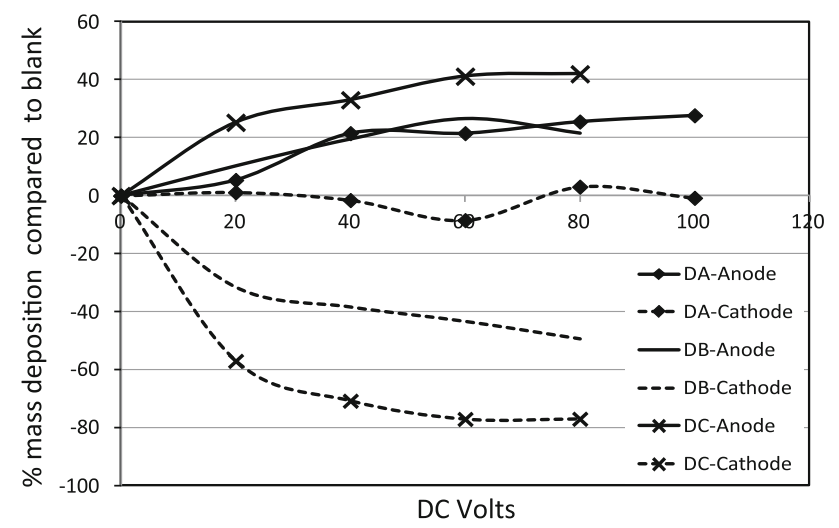

Fig. 6 Incremental and reduced asphaltene deposition in anode and cathode

the oil is diluted. Considering the worst case scenario, when the oil is diluted $100 \%$ (50:50), $180 \%$ deposition control is achieved with the application of $60 \mathrm{~V}$ compared with almost no control when neat oil is used.

The above observations clearly suggest the colloidal nature of asphaltene with excess negative surface charge.
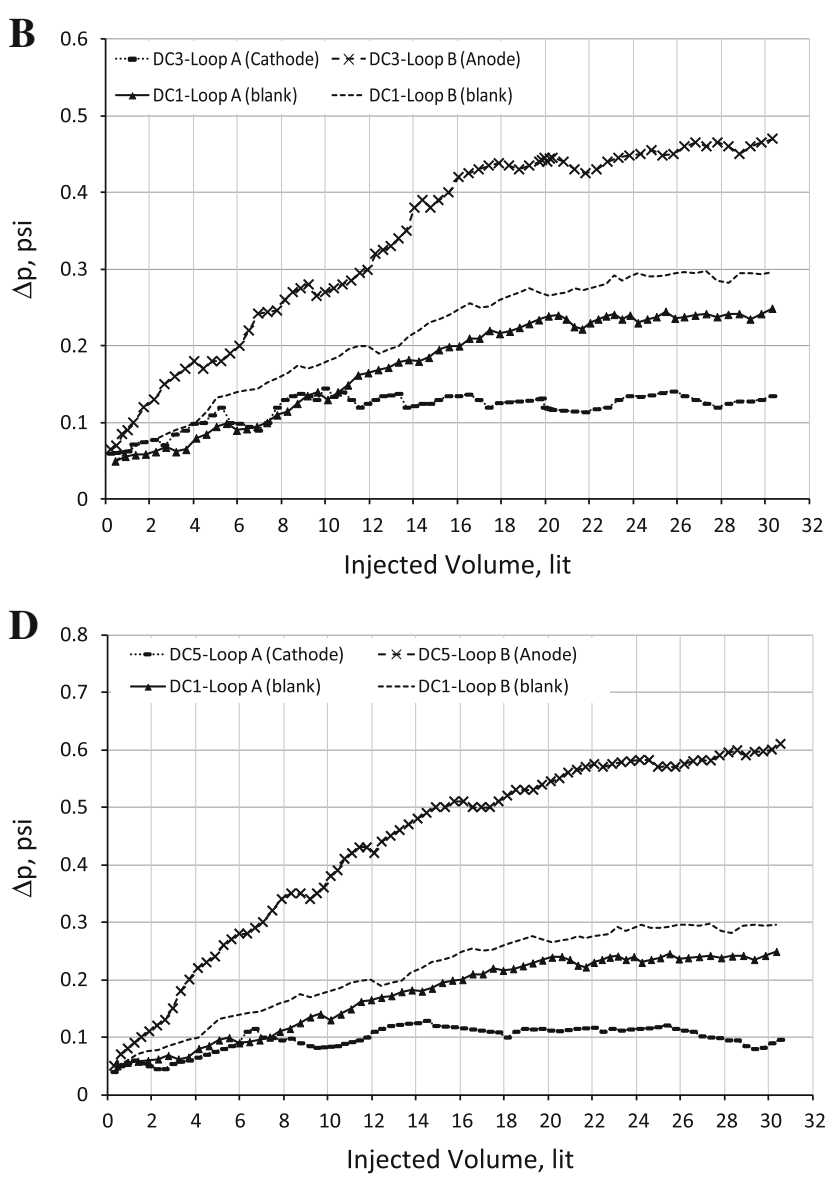

DC-4 (60 V, 50:50 oil). d Pressure build-up during blank DC-1 and test DC-4 (80 V, 50:50 oil)

Negative surface charge on asphaltenes arises upon dissociation of acidic peripheral functional groups such as carboxylic acids and sulphonic acids. (Jada and Salou 2002; Vega et al. 2009). The positive surface charge arises upon protonation of basic nitrogen-containing functional groups such as pyridine. Parra-Barraza et al. (2003) measured zeta potential of heptane-diluted crude oils and found that at acidic $\mathrm{pH}$ asphaltene goes below isoelectric point and becomes positively charged whereas at neutral and higher $\mathrm{pH}$ de-protonation occurs resulting negative surface charge. Since the crude oil under present investigation originated in a carbonate reservoir with basic $\mathrm{pH}$ environment, it can be assumed that the asphaltenes have exceeded isoelectric point and acquired negative charges. Two possible scenarios that may be encountered in asphaltene-resin system are (A) asphaltene is negatively charged and resin is positively charged and (B) asphaltene is positively charged and resin is negatively charged. These scenarios and the effect of heptane dilutions are depicted through Fig. 7. Careful analysis of these two scenarios show that in case of scenario A, higher the dilution of crude 
Fig. 7 Possible depletion of surface charge of colloidal micelle due to heptane dilution. Case 1 (top) Asphaltene contains excess negative charge. Due to heptane dilution, positively charged resins go away resulting increasing negative charge on the micelle. Case 2 (bottom) opposite phenomenon would occur if charges on asphaltene and resins are reversed
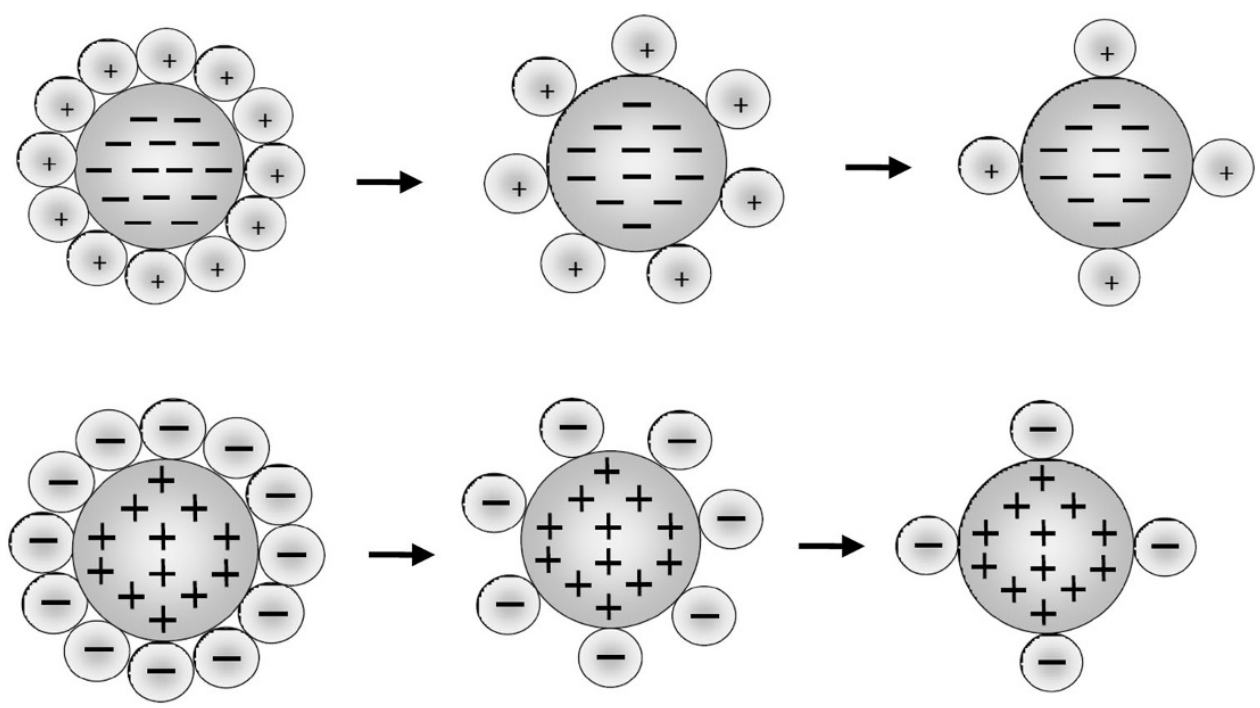

3. The amount of $n$-heptane used to dilute the crude oil determines the surface charge of asphaltene-resin colloids which in turn affects the deposition rate and quantity. Higher the dilution, higher is the effect of DC potential in terms of deposition rate and quantity.

Acknowledgments The authors are grateful to the Petroleum Institute, Abu Dhabi, UAE for providing the laboratory facilities to conduct this research work and other financial assistance.

Open Access This article is distributed under the terms of the Creative Commons Attribution License which permits any use, distribution, and reproduction in any medium, provided the original author(s) and the source are credited.

\section{References}

Alkafeef SF (2001) An investigation of the stability of colloidal asphaltene in petroleum reservoirs. Presented at the SPE international symposium on oilfield chemistry, Houston, 13-16 Feb 2001 (SPE 65018)

Andersen SI, Speight JG (2001) Petroleum resins: separation, character, and role in petroleum. Pet Sci Technol 19:1-34

Asomaning S, Watkinson AP (2000) Petroleum stability and heteroatom species effects in fouling of heat exchangers by asphaltenes. Heat Transf Eng 21(3):10-16

Behar E, Hasnaoui N, Achard C, Rogalski M (1998) Study of asphaltene solutions by electrical conductivity measurements. Oil Gas Sci Technol 53(1):41-50

Belhaj H, Khalifeh HA (2013) Asphaltene stability in crude oil during production process. J Pet Environ Biotechnol 4(3):1-5

Fotland P, Anfindsen H (1996) Electrical conductivity of asphaltenes in organic solvents. Fuel Sci Technol Int 14(1/2):101-115

Gonzalez G, Neves GBM, Saraiva SM, Lucas EF, De Sousa MA (2003) Electro-kinetic characterization of asphaltenes and the asphaltenes-resins interaction. Energy Fuels 17:879-886

Goual L, Firoozabadi A (2002) Measuring asphaltenes and resins, and dipole moment in petroleum fluids. AIChE $\mathrm{J}$ 48(11): 2646-2662 little or no deposition occurred on cathode surface. 
Goual L, Firoozabadi A (2004) Effect of resins and DBSA on asphaltene precipitation from petroleum fluids. AIChE J 50(2):470-479

Groenzin H, Mullins OC (2000) Molecular size and structure of asphaltenes from various sources. Energy Fuels 14:677-684

Hashmi SM, Firoozabadi A (2012) Controlling nonpolar colloidal asphaltene aggregation by electrostatic repulsion. Energy Fuel 26:4438-4444

Idem RO, Ibrahim $\mathrm{HH}$ (2002) Kinetics of $\mathrm{CO}_{2}$-induced asphaltene precipitation from various Saskatchewan crude oils during $\mathrm{CO}_{2}$ miscible flooding. J Pet Sci Eng 35(3):233-246

Igor NE, Aleksander PL (2010) Electrical conductivity and dielectric properties of solid asphaltenes. Energy Fuels 24(7):3959-3969

Jada A, Salou M (2002) Effects of the asphaltene and resin contents of the bitumens on the water-bitumen interface properties. J Pet Sci Eng 33:185-193

James W, Richard RM (1963) The electrophoretic mobility of asphaltenes in nitromethane. J Colloid Sci 18:223-236

Janusz M, Jablonski W (2000) Electrochemical properties of asphaltene particles in aqueous solutions. J Dispers Sci Technol 21(6):785-802

Khvostichenko DS, Andersen SI (2009) Electrodeposition of asphaltenes preliminary studies on electrodeposition from oil-heptane mixtures. Energy Fuels 23:811-819

Kokal S, Thompson T, Laurier S, Selim S (1995) Electrokinetic and adsorption properties of asphaltenes. Coll Surf A Physicochem Eng Asp 94:253-265

Leon O, Rogel E, Torres G, Lucas A (2000) Electrophoretic mobility and stabilization of asphaltenes in low conductivity media. Pet Sci Technol 18:913-927

Leontaritis KJ (1989) Asphaltene deposition: a comprehensive description of problem manifestations and modeling approaches.
Presented at SPE production operations symposium, Oklahoma City, 13-14 Mar 1989 (SPE 18892)

Leontaritis KJ, Mansoori GA (1987) Asphaltene flocculation during oil production and processing: a thermodynamic-colloidal model. Presented at SPE international symposium on oilfield chemistry, San Antonio, 4-6 Feb 1987 (SPE 16258)

Lichaa PM, Herrera L (1975) Electrical and other effects related to the formation and prevention of asphaltene deposition problem in Venezuelan crudes. Presented at the SPE oilfield chemistry symposium, Dallas, 13-14 Jan 1975 (SPE 5304)

Nasser A, Belhaj H (2010) Modeling of crude oil asphaltenes deposition: in-depth colloidal prospective. . Presented at SPE production and operations conference and exhibition, Tunis, 8-10 Jun 2010 (SPE 136087)

Parra-Barraza H, Hernandez-Montiel D, Lizardi J, Hernandez ZJ, Urbina RH, Valdez M (2003) The zeta potential and surface properties of asphaltenes obtained with different crude oil $/ n$ heptane proportions. Fuel 82:869-874

Speight JG (1998) The chemistry and technology of petroleum, 3rd edn. Marcel Dekker, New York

Taylor SE (1998) The electro-deposition of asphaltenes and implications for asphaltene structure and stability in crude and residual oils. Fuel 77:821-828

Vega SS, Herrera UR, Valdez CM, Galeana LC (2009) The zeta potential of solid asphaltene in aqueous solutions and in 50:50 water + ethylene glycol $(\mathrm{v} / \mathrm{v})$ mixtures containing ionic surfactants. J Pet Sci Eng 69:174-180

Yen TF, Chilingarian GV (1994) Asphaltenes and asphalts-1. Elsevier, 1st edn. ISBN: 978-0-444-88291-2 